Dikirim: 20 Juni 2017

Diterbitkan: 1 November 2017

\section{Pengetahuan, efikasi diri dan praktik penjamah makanan tentang keamanan pangan pada industri rumah tangga pangan}

Knowledge, self-efficacy, and handling practices on food safety in home industry

Jimmi Kifly Putra Sihombing ${ }^{1}$, Susi Ari Kristina ${ }^{2}$, Retna Siwi Padmawati ${ }^{1}$

\section{Abstract}

Purpose: This study aimed to explore the sociodemographic characteristics, experience, knowledge level, self-efficacy of food handlers at home industry in Ambon and their relation to food safety practices. Methods: This research was a cross sectional study with 51 samples of home industry with 135 respondents. Statistical analysis used chi square and logistic regression tests. Results: There was a correlation between education level, training, knowledge with self-efficacy. There is a significant association of education level, self-efficacy, knowledge with food safety practice of food handler. Conclusion: Food safety in home industry depends on food handling practices. This study suggested to increase the monitoring system for food handlers in order to prevent foodborne disease.

Keywords: food safety; knowledge; self-efficacy; practices; food handlers; home industry

\footnotetext{
${ }^{1}$ Departemen Perilaku Kesehatan, Lingkungan, dan Kedokteran Sosial, Fakultas Kedokteran, Universitas Gadjah Mada (Email: jimmikps@gmail.com)

${ }^{2}$ Departemen Farmasetika, Fakultas Farmasi, Universitas Gadjah Mada
} 


\section{PENDAHULUAN}

Keamanan pangan merupakan isu kesehatan masyarakat yang penting (1). Penyakit bawaan makanan merupakan penyebab utama morbiditas dan mortalitas (2). Secara global, diperkirakan 1,8 juta orang meninggal setiap tahun disebabkan diare. Sebagian besar penyakit diare disebabkan karena makanan dan minuman yang terkontaminasi (3). Center for Disease Control and Prevention (CDC) melaporkan satu dari enam warga Amerika sakit karena mengonsumsi makanan dan minuman terkontaminasi dan tercatat 3000 orang meninggal setiap tahun (4).

Wabah berkaitan dengan perilaku penjamah makanan (5). Wabah pada penyakit bawaan makanan (foodborne disease) mayoritas disebabkan oleh malpraktik industri kecil rumah tangga sejak tahap persiapan sampai proses produksi (6). Penjamah makanan merupakan penyebab utama kontaminasi makanan (7). Kontaminasi ini disebabkan karena penjamah makanan tidak mempraktikkan sistem sanitasi dan higiene produksi makanan. Penjamah makanan cenderung mengabaikan penanganan makanan yang tepat (8).

Balai Pengawasan Obat dan Makanan Ambon tahun 2015 melakukan pengujian 581 sampel produk makanan, dan diperoleh 64 produk tidak memenuhi persyaratan. Dari 64 produk yang tidak memenuhi persyaratan terdapat 55 (84\%) produk yang berasal dari industri rumah tangga pangan (IRTP) dengan perincian sebanyak 15 (23\%) produk yang sudah memiliki nomor produk industri rumah tangga (PIRT) dan 39 (61\%) yang belum memiliki nomor PIRT (9).

IRTP di Kota Ambon berpengaruh dalam menghasilkan produk yang tidak memenuhi persyaratan. Sekitar 84\% dari total produk ditemukan tidak memenuhi persyaratan, sehingga perlu perhatian khusus terkait penanganan makanan. Produsen harus menjamin kemamanan produk yang beredar di pasar (10). Penelitian terkait dengan pengetahuan, efikasi diri, dan praktik keamanan pangan pada IRTP sangat perlu dilakukan di agar diketahui masalah yang dihadapi. Penelitian ini bertujuan untuk mengetahui karakteristik sosiodemografi, pengalaman, tingkat pengetahuan, efikasi diri penjamah makanan pada IRTP di Kota Ambon dan keterkaitannya pada praktik keamanan pangan.

\section{METODE}

Penelitian dilakukan menggunakan survei kepada 135 penjamah makanan di 51 industri di Kota Ambon. Pengambilan sampel dilakukan melalui quota sampling dengan kriteria inklusi dan eksklusi. Kriteria inklusi adalah IRTP yang mempunyai tenaga kerja 2 orang atau lebih, aktif melakukan produksi dan produk yang dihasilkan didistribusikan ke pasar, bersedia menjadi responden, berada di lokasi pada saat penelitian dilakukan. Sedangkan yang menjadi kriteria eksklusi adalah tidak bersedia menjadi responden, lama bekerja kurang dari 1 tahun sebagai penjamah makanan.

Pengetahuan dikategori menjadi pengetahuan baik dan kurang. Jika jumlah nilai benar $\geq 13,08$ diberikan tingkat pengetahuan dengan kategori baik dan jika jumlah nilai benar $<13,08$ diberikan tingkat pengetahuan dengan kategori kurang. Jika jumlah nilai benar $\geq 43,97$ diberikan tingkat efikasi diri dengan kategori baik dan jika jumlah nilai benar <43,97 diberikan tingkat efikasi diri dengan kategori kurang. Keamanan pangan baik jika jumlah nilai $\geq 15$ dan jika jumlah nilai $<15$ diberikan penilaian dengan kategori kurang.

\section{HASIL}

Tabel 1 menunjukkan mayoritas responden berusia 21-30 tahun, laki-laki lebih banyak, berpendidikan SMA, lama bekerja 1-5 tahun. Empat puluh tujuh persen belum pernah mengikuti pelatihan. Penjamah makanan dengan pimpinan yang belum pernah mengikuti pelatihan sebanyak 31 orang (22,96\%). Terdapat $20(39,22 \%)$ sarana produksi yang belum memiliki nomor IRTP.

Tabel 1. Ciri demografi penjamah makanan IRTP

\begin{tabular}{|c|c|}
\hline Ciri & $\%(n=135)$ \\
\hline \multicolumn{2}{|l|}{ Umur } \\
\hline$<20$ tahun $(\mathrm{n}=16)$ & 11,85 \\
\hline $21-30$ tahun $(n=67)$ & 49,63 \\
\hline $31-40$ tahun $(n=29)$ & 21,48 \\
\hline $41-50$ tahun $(n=14)$ & 10,37 \\
\hline$>50$ tahun $(\mathrm{n}=9)$ & 6,67 \\
\hline \multicolumn{2}{|l|}{ Jenis Kelamin } \\
\hline Laki-laki $(n=75)$ & 55,56 \\
\hline Perempuan $(\mathrm{n}=60)$ & 44,44 \\
\hline \multicolumn{2}{|l|}{ Pendidikan } \\
\hline Tidak sekolah $(\mathrm{n}=1)$ & 0,74 \\
\hline Tamat SD $(n=12)$ & 8,89 \\
\hline Tamat SMP $(n=33)$ & 24,44 \\
\hline Tamat SMA $(\mathrm{n}=82)$ & 60,74 \\
\hline Tamat Perguruan Tinggi $(n=7)$ & 5,19 \\
\hline \multicolumn{2}{|l|}{ Lama bekerja } \\
\hline $1-5$ tahun $(n=91)$ & 67,41 \\
\hline $6-10$ tahun $(n=30)$ & 22,22 \\
\hline$>50$ tahun $(n=14)$ & 10,37 \\
\hline \multicolumn{2}{|l|}{ Kepemilikan nomor PIRT } \\
\hline Tidak ada $(n=20)$ & 39,22 \\
\hline Ada $(n=31)$ & 60,78 \\
\hline \multicolumn{2}{|l|}{ Pelatihan } \\
\hline Tidak pernah $(n=64)$ & 47,41 \\
\hline Pernah $(n=71)$ & 52,59 \\
\hline \multicolumn{2}{|l|}{ Pelatihan pimpinan } \\
\hline Tidak pernah $(\mathrm{n}=31)$ & 22,96 \\
\hline Pernah $(n=104)$ & 77,04 \\
\hline
\end{tabular}


Pengukuran pengetahuan diperoleh nilai rata-rata 13,08. Hasil penelitian menunjukkan tingkat pengetahuan kategori kurang berjumlah lebih banyak dibandingkan kategori baik. Pengetahuan kategori kurang berjumlah 78 orang $(57,78 \%)$ sedangkan kategori baik berjumlah 57 orang $(42,22 \%)$.

Sebanyak 14 pernyataan terkait efikasi diri keamanan pangan disampaikan kepada responden. Nilai rata-rata efikasi diri penjamah makanan adalah 43,97 dengan simpangan deviasi sebesar $+4,67$ pada range skor antara 14 sampai 56. Hasil penelitian menunjukkan bahwa tingkat efikasi diri dengan kategori baik memiliki jumlah yang lebih banyak dibandingkan dengan kategori kurang. Efikasi diri dengan kategori kategori baik berjumlah 74 orang $(54,81 \%)$ dan kurang berjumlah 61 orang $(45,19 \%)$.

Sebanyak 19 pernyataan terkait praktik keamanan pangan disampaikan kepada responden. Adapun hasil pengukuran pengetahuan diperoleh nilai rata-rata 77,53 dengan simpangan deviasi sebesar +9,39 pada range skor antara 19 sampai 95. Pemberian kategori dilakukan berdasarkan nilai rata-rata. Jika jumlah nilai benar $\geq 77,53$ diberikan tingkat praktik dengan kategori baik dan jika jumlah nilai benar $<77,53$ diberikan tingkat praktik dengan kategori kurang. Penelitian ini menunjukkan tingkat praktik kategori kurang berjumlah 64 orang $(47,41 \%)$ sedangkan kategori baik berjumlah 71 orang $(52,59 \%)$.

Observasi dilakukan untuk mengetahui kondisi yang sebenarnya terjadi dilapangan. Hasil observasi ini dilakukan sebagai alat pembanding antara jawaban yang diberikan oleh responden dengan keadaan yang sebenarnya. Uji normalitas menunjukkan bahwa data tidak terdistribusi secara normal. Pemberian kategori dilakukan berdasarkan nilai tengah. Observasi tentang keamanan pangan pada IRTP di Kota Ambon menunjukkan bahwa kategori kurang sebanyak 17 (44,74\%) dan baik sebanyak 21 (55,26\%).

Penelitian ini menemukan hubungan umur dengan efikasi diri penjamah makanan di IRTP di Kota Ambon. Uji statistik pada jenis kelamin diperoleh angka signifikasi nilai $\mathrm{p}=0,075$ yang artinya tidak terdapat hubungan antara jenis kelamin dengan efikasi diri penjamah makanan di IRTP di Kota Ambon.

Uji statistik pada tingkat pendidikan diperoleh angka signifikasi $p=0,008$, yang artinya terdapat hubungan antara tingkat pendidikan dengan efikasi diri penjamah makanan di IRTP di Kota Ambon. Berdasarkan uji statistik pada lama bekerja diperoleh angka signifikasi $\mathrm{p}=0,316$ ( $\mathrm{p}>0,05)$ yang artinya tidak terdapat hubungan antara tingkat pendidikan dengan efikasi diri penjamah makanan di IRTP di Kota Ambon.
Uji statistik pada kepemilikan PIRT diperoleh angka signifikasi $p=0,114(p>0,05)$ yang artinya tidak terdapat hubungan antara kepemilikan nomor PIRT dengan efikasi diri penjamah makanan.

Uji statistik pada pelatihan diperoleh angka signifikansi $\mathrm{p}=0.035(\mathrm{p}<0,05)$ yang artinya terdapat hubungan antara pelatihan dengan efikasi diri penjamah makanan di IRTP di Kota Ambon. Uji statistik pada pengalaman mengikuti pelatihan oleh pimpinan, diperoleh angka signifikasi $p=0,471 \quad(p>0,05)$ yang artinya tidak terdapat hubungan antara pelatihan pimpinan dengan efikasi diri penjamah makanan di IRTP di Kota Ambon.

Uji statistik pengetahuan diperoleh angka signifikansi $\mathrm{p}=0,000(\mathrm{p}<0,05)$ yang artinya terdapat hubungan antara pelatihan dengan efikasi diri penjamah makanan di IRTP di Kota Ambon.

Uji statistik pada praktik diperoleh angka signifikansi $p=0,000(p<0,05)$ yang artinya ada hubungan antara efikasi diri dengan praktik penjamah makanan di IRTP di Kota Ambon.

Uji statistik pada umur diperoleh angka signifikansi $p=0,113(p>0,05)$ yang artinya tidak ada hubungan antara umur dengan praktik penjamah makanan di IRTP di Kota Ambon. Uji statistik pada jenis kelamin diperoleh angka signifikasi $p=0,217 \quad(p>0,05)$ yang artinya tidak ada hubungan antara jenis kelamin dengan praktik penjamah makanan.

Uji statistik pada tingkat pendidikan diperoleh angka signifikasi $\mathrm{p}=0,001 \quad(\mathrm{p}<0,05)$ yang artinya ada hubungan antara tingkat pendidikan dengan praktik penjamah makanan di IRTP di Kota Ambon. Berdasarkan uji statistik pada lama bekerja diperoleh angka signifikasi $\mathrm{p}=0,323(\mathrm{p}>0,05)$ yang artinya tidak terdapat hubungan antara lama bekerja dengan praktik penjamah makanan di IRTP di Kota Ambon. Uji statistik pada kepemilikan PIRT diperoleh angka signifikasi $\mathrm{p}=0,412(\mathrm{p}>0,05)$ yang artinya tidak terdapat hubungan antara kepemilikan nomor PIRT dengan praktik penjamah makanan di IRTP di Kota Ambon.

Hasil uji statistik terhadap praktik diperoleh angka signifikansi nilai $\mathrm{p}=0,005$ yang artinya bahwa terdapat hubungan antara pengetahuan dengan praktik penjamah makanan di IRT) di Kota Ambon.

Variabel efikasi diri mempunyai nilai odds ratio (OR) yang paling besar yakni 3,403 artinya efikasi diri penjamah makanan memiliki peluang 3,403 kali lebih besar pengaruhnya untuk melakukan praktik keamanan pangan dalam IRTP di Kota Ambon. Variabel berikutnya adalah pendidikan yang mempunyai nilai odds ratio (OR)=2,885 artinya pendidikan penjamah makanan memiliki peluang 
2,885 kali lebih besar untuk melakukan praktik yang baik dalam IRTP di Kota Ambon. Tabel 2 menunjukkan nilai R2 sebesar $11,86 \%$ artinya efikasi dari dan pendidikan memengaruhi praktik penjamah makanan sebsar $11,86 \%$, sisanya dipengaruhi oleh faktor yang lain.

Tabel 2. Faktor utama yang memengaruhi praktik penjamah makanan di IRTP di Kota Ambon.

\begin{tabular}{lllllll}
\hline Variabel & OR & SE & Z & p- value & CI (95\%) & R2 \\
\hline Efikasi diri & 3,403 & 1,287 & 3,24 & 0,001 & $1,622-$ & 0,1186 \\
& & & & & 7,141 & \\
Pendidikan & 2,885 & 1,158 & 2,64 & 0,008 & $1,314-$ & \\
& & & & & 6,335 & \\
\hline
\end{tabular}

\section{BAHASAN}

Penelitian ini menemukan faktor yang paling berpengaruh terhadap efikasi diri penjamah makanan di IRTP adalah tingkat pendidikan. Tingkat pendidikan SMA dan perguruan tinggi dominan memiliki efikasi diri yang baik. Penelitian ini sejalan dengan penelitian yang lain yang menyatakan bahwa tingkat pendidikan seseorang memiliki korelasi yang positif terhadap efikasi diri karyawan (12). Semakin tinggi tingkat pendidikan seseorang, wawasan dan logika berpikir cenderung akan lebih baik dan hal ini akan meningkatkan efikasi diri seseorang. Efikasi diri merupakan kemampuan seseorang untuk mampu melaksanakan tugas dengan baik. Salah satu faktor yang diindentifikasi memenga- ruhi kognitif efikasi adalah enactive yaitu belajar dari pengalaman langsung (13). Semakin tinggi tingkat pendidikan, maka pengalaman belajar individu menjadi lebih banyak dan tentunya akan meningkatkan efikasi diri. Efikasi diri yang baik akan memengaruhi keyakinan seseorang untuk mampu menyelesaikan tugas tertentu, yang juga memengaruhi tingkat usaha dan ketekunan seseorang untuk menyelesaikan tugas yang sulit (14).

Faktor pengalaman mengikuti pelatihan yakni penjamah makanan. Pelatihan pada penjamah makanan mempunyai dampak yang signifikan dalam memengaruhi efikasi diri penjamah makanan. Pemberian pelatihan berdampak positif terhadap efikasi diri keamanan pangan (15) dan keikutsertaan individu dalam pelatihan memiliki efek yang signifikan terhadap praktik penanganan pangan (16). Terbentuknya efikasi diri sangat erat kaitannya ketika seseorang melihat pengalaman orang lain (vicarious learning) (17). Ketika melihat orang lain melakukan suatu pekerjaan yang mirip dengan dirinya, individu cenderung akan lebih percaya diri bahwa individu tersebut mampu melakukannya. Program pelatihan sangat penting untuk menambah pengetahuan mereka dalam penanganan pangan (18).

Berdasarkan hasil analisis secara bivariabel diperoleh bahwa variabel pengetahuan mempunyai signifikansi terhadap variabel efikasi diri yang artinya pengetahuan penjamah makanan mempunyai dampak signifikan dalam memengaruhi efikasi diri penjamah makanan. Penelitian sebelumnya menemukan pengetahuan berkorelasi positif dengan efikasi diri seseorang (19). Penelitian yang lain yang menunjukkan hasil yang sama dilakukan pada masyarakat China yang tinggal di U.S dan menyebutkan bahwa efikasi diri menjadi indikator kuat dalam praktik keamanan pangan (20).

Pengetahuan merupakan pedoman dalam membentuk tindakan seseorang (21). Jika dikaitkan dengan keamanan pangan, individu yang memiliki pengetahuan yang baik tentang keamanan akan cenderung lebih yakin dan mampu untuk melakukan praktik keamaman pangan. Penyebaran informasi yang berkaitan dengan pengetahuan keamanan pangan sangat perlu dilakukan karena memiliki korelasi positif terhadap efikasi diri. Semakin tinggi pengetahuan, maka mendorong peningkatan efikasi diri penjamah makanan.

Efikasi diri penjamah makanan berdampak yang signifikan dalam memengaruhi praktik penjamah makanan. Penelitan yang sejalan dengan itu menyatakan bahwa efikasi diri keamanan pangan mempunyai indikasi yang cukup kuat terhadap perubahan perilaku positif (15). Penelitian pada pekerja di Ghana menyebutkan bahwa efikasi diri penjamah makanan mempunyai korelasi yang kuat terhadap kualitas penjamah makanan dalam pekerjaan (12). Penelitian yang lain pada masyarakat China yang tinggal di Amerika. menyebutkan bahwa efikasi diri menjadi indikator kuat praktik keamanan pangan (20).

Efikasi diri adalah keyakinan seseorang terhadap kemampuan dirinya untuk melakukan suatu perilaku (22). Penjamah makanan yang mempunyai efikasi diri yang tinggi cenderung akan memiliki keyakinan yang tinggi untuk mampu melaksanakan pekerjaannya dengan baik. Pada situasi yang sulit atau pekerjaan yang sulit, penjamah makanan yang mempunyai efikasi diri yang rendah cenderung kurang berusaha atau mudah menyerah, akan tetapi penjamah makanan yang memiki efikasi yang tinggi akan berusaha keras untuk menyelesaikan tantangannya (14).

Berdasarkan hasil analisis secara bivariabel diperoleh bahwa faktor karakteristik yang secara signifikan berpengaruh terhadap praktik penjamah 
makanan pada IRTP di Kota Ambon adalah faktor tinggi dominan memiliki praktik yang baik, sedangkan tingkat pendidikaan tidak sekolah sampai dengan SMP memiliki efikasi diri baik sebanyak sekitar 32,61\%.

Penelitian yang lain yang memiliki hasil yang sama dengan ini dilakukan pada penjamah daging di Romania barat yang menyebutkan bahwa tingkat pendidikan berhubungan dengan praktik keamanan pangan (23). Seseorang yang memiliki tingkat pendidikan yang tinggi, cenderung mempunyai wawasan yang lebih luas karena individu tersebut belajar lebih banyak dibandingkan dengan individu yang mempunyai pendidikan yang lebih rendah. Wawasan yang lebih banyak inilah yang membuat individu menjadi lebih percaya diri dan lebih yakin mampu untuk menyelesaikan pekerjaan.

Berdasarkan hasil analisis secara bivariabel diperoleh bahwa pengetahuan penjamah makanan mempunyai dampak yang signifikan dalam memengaruhi praktik penjamah makana. Penelitan ini dikuatkan oleh penelitian pada pekerja pemotong daging yang menyatakan bahwa tingkat pengetahuan pemotong daging mempunyai dampak yang signifikan terhadap praktik keamanan pangan (23). Begitu juga penelitian yang dilakukan pada penjamah makanan migrant di romania barat yang menyatakan pengetahuan penjamah makanan berdampak signifikan terhadap praktik keamanan pangan (16).

Penelitian yang juga memiliki hasil yang sama juga dilakukan pada penjamah makanan di Ghana menyatakan bahwa pengetahuan mempunyai korelasi yang postif terhadap praktik keamanan pangan dan Abdul-Mutalib pada penjamah makanan di Kuala Pilah-Malaysia (8,24). Penjamah makanan harus memiliki keahlian dan pengetahuan untuk penanganan makanan yang aman (18). Untuk mencegah penyakit bawaan makanan, pemilik industri makanan mempunyai akses dan memperbaiki pengetahuan, higiene perorangan, higiene bekerja untuk mewujudkan keamanan pangan (25).

Pada saat dilakukan observasi di IRTP di Kota Ambon, sebagian penjamah makanan tidak menerapkan praktik keamanan pangan. Hasil observasi menunjukkan bahwa masih terdapat praktik keamanan pangan yang berisiko terhadap munculnya food borne disease seperti tidak tersedia sarana cuci tangan yang dilengkapi dengan sabun dan alat pengering, tempat sampah tertutup, tidak menggunakan pakaian kerja, penutup kepala, masker dan sarung tangan. Praktik ini sangat berisiko terjadi bahaya mikrobiologi. Praktik ini harus diatasi untuk mencegah terjadinya food borne disease. Wabah penyakit penyakit bawaan makanan pendidikan. Tingkat pendidikan SMA dan perguruan disebabkan oleh kurangnya fasilitas higiene. Faktor yang paling memengaruhi adalah toilet yang tidak berfungsi secara memadai, air, sabun dan alat pengering yang bersih (26).

\section{SIMPULAN}

Faktor utama yang memengaruhi praktik penjamah makanan adalah efikasi diri dan pengetahuan. Keamanan pangan di industri rumah tangga bergantung pada praktik penanganan makanan. Perlu sistem pemantauan penanganan makanan agar tidak terjadi food borne disease.

\begin{abstract}
Abstrak
Tujuan: Untuk mengetahui karakteristik sosiodemografi, pengalaman, tingkat pengetahuan, efikasi diri penjamah makanan pada IRTP di Kota Ambon dan keterkaitannya pada praktik keamanan pangan. Metode: Penelitian cross-sectional pada 51 industri rumah tangga pangan dengan jumlah responden sebanyak 135 orang. Uji chi square untuk analisis bivariabel dan regresi logistik untuk analisis multivariabel. Hasil: Terdapat hubungan tingkat pendidikan, pelatihan, pengetahuan dengan efikasi diri keamanan pangan penjamah makanan pada industri rumah tangga pangan. Simpulan: Penelitian ini menyatakan bahwa keamanan pangan di industri rumah tangga bergantung pada praktik penanganan makanan. Penelitian ini menyarankan untuk meningkatkan sistem pemantauan penangan makanan agar tidak terjadi food borne disease.
\end{abstract}

Kata kunci: keamanan pangan; pengetahuan; efikasi diri; praktik; penjamah makanan; industri rumah tangga pangan

\section{PUSTAKA}

1. World Health Organization. Food safety and foodborne illness. In: Fact Sheet N 237 Word Health Organization (WHO); 2007.

2. Chan SF, Chan Z. A Review of Foodborne Disease Outbreaks From 1996 on Food Safety Promotion. J Food Saf. 2007;28(2008):276-99.

3. World Health Organization. Five Keys To Safer Food Manual Safer Food Manual. 2006.

4. CDC. CDC and Food Safety. 2016(March).

5. Thimoteo D, Stedefeldt E, Rosso VV De. The role of theoretical food safety training on Brazilian food handlers ' knowledge , attitude and practice. Food Control [Internet]. Elsevier Ltd. 2014;43:167-74. 
Phillip S, Anita E. Efficacy of the theory of planned behaviour model in predicting safe food handling practices. Food Control. Elsevier Ltd. 2010;21(7):983-7.

6. Campos AKC, Cardonha ÂMS, Pinheiro LBG, Ferreira NR, Azevedo PRM de, Stamford TLM. Assessment of personal hygiene and practices of food handlers in municipal public schools of Natal, Brazil. Food Control [Internet]. Elsevier Ltd. 2009;20(9):807-10.

7. Abdul-Mutalib N-A, Abdul-Rashid M-F, Mustafa S, Amin-Nordin S, Hamat RA, Osman M. Knowledge, attitude and practices regarding food hygiene and sanitation of food handlers in Kuala Pilah, Malaysia. Food Control. 2012;27(2):289-93.

8. Balai POM Ambon. Laporan Kinerja Balai POM di Ambon Tahun 2015; 2016.

9. World Health Organization. Food Safety. In: Food Safety ; Fact sheet N 399. 2015. p. 1011-1011.

10. Dahlan MS. 13 Penyakit Statistik. 7th ed. Jakarta Indonesia: Sagung Seto; 2010.

11. Mensah AO, Lebbaeus A. The Influence of Employees' Self-Efficacy on Their Quality of Work Life: The Case of Cape Coast, Ghana. Int J Bus Soc Sci[Internet]. 2013;4(2).

12. Bandura A. Toward a unifying theory of behavioral change [Internet]. Psychological Review; 1977. p. 191-215. Available from: http://www.apa.org/pubs/journals/rev/

13. Bayramoğlu G, Șahin M, DeVellis BM, Youssef CM, Luthans F, Youssef CM, et al. Self-Efficacy in the workplace: Implications for motivation and performance. J Manage [Internet]. 2013;3(2):154-7.

14. Beavers AS, Murphy L, Richards JK. Investigating Change in Adolescent Self-Efficacy of Food Safety Through Educational Interventions. J Food Sci Educ. 2015;14(2):54-9.

15. Yee P, Lin K, Marian J, Watkin J, Nursheena S, Zain M. Evaluation of basic knowledge on food safety

26. food safety arsenal. Food Qual. 2002;9(5):45-53 and food handling practices amongst migrant food handlers in Peninsular Malaysia. Food Control [Internet]. Elsevier Ltd; 2016;70:64-73.

16. Pajares F. Overview of Social Cognitive Theory and of self efficacy. 2002; Available from: https://www.uky.edu/ eushe2/Pajares/eff.html

17. Ansari-Lari M, Soodbakhsh S, Lakzadeh L. Knowledge, attitudes and practices of workers on food hygienic practices in meat processing plants in Fars, Iran. Food Control [Internet]. Elsevier Ltd; 2010;21(3):260-3.

18. Sung S-C, Huang H-C, Lin M-H. Relationship between the knowledge, attitude, and self-efficacy on sexual health care for nursing students. J Prof Nurs[Internet]. 2015;31(3):254-61.

19. Liu B, Cho S. Food Safety Practices among Chinese in the U.S; 2011

20. Maulana HD. Promosi Kesehatan. Penerbit Buku Kedokteran EGC; 2009.

21. Glanz K, Rimer BK, Viswanath K. Health Behaviour and Health Education. Four Editi. United States of America: Jossey Bass A Wiley Imprint; 2008.

22. Jianu C, Golet I. Knowledge of food safety and hygiene and personal hygiene practices among meat handlers operating in western Romania. Food Control. 2014;42:214-9.

23. Kunadu AP, Ofosu DB, Aboagye E, Tano-debrah K. Food safety knowledge, attitudes and self-reported practices of food handlers in institutional foodservice in Accra, Ghana. Food Control [Internet]. Elsevier Ltd; 2016;69:324-30.

24. Ismail FH, Chik CT, Muhammad R, Mat N. Food Safety Knowledge and Personal Hygiene Practices amongst Mobile Food Handlers in Shah Alam, Selangor. Procedia - Soc Behav Sci [Internet]. Elsevier B.V.;2016;222:290-8.

25. Michaels B. Handwashing: an effective tool in the 